\title{
Feature Fatigue, IT Fashion and IT Consumerization - Is There a Relationship?
}

\author{
Luiz Antonio Slongo ', Mery Blanck ${ }^{2}$, Rafael Alfonso Brinkhues ${ }^{*^{3}}$, Rafael Mello Oliveira ${ }^{4}$
}

\begin{abstract}
Based on the concepts of Feature Fatigue, IT Fashion and IT Consumerization, this paper aims to investigate the relationships between them answering two questions: (1) does the phenomenon of IT Fashion result in Feature Fatigue? (2) Will the concept of Feature Fatigue cause the same effect when looking from the point of view of the IT Consumerization in the corporate environment? The research addresses these questions through two techniques: a laddering and a survey. Albeit tenuously, the results provide evidence that consumption motivated by IT Fashion leads to Feature Fatigue. This study contributes to management research by attempting at the phenomenon described from a multidisciplinary perspective, also contributing to management practice, specifically for marketing managers trying to understand the experiences and expectations of consumers, and also for IT managers engaged in the design of governance policies regarding the use of personal devices by employees in this context.
\end{abstract}

Keywords: feature fatigue, IT fashion, IT consumerization.

Submitted: June 28th 2015 / Approved: December 6th 2015

\section{Introduction}

Technological advances have enabled manufacturers to add many features to new products, especially their electronics and IT devices, at a relatively small cost per added feature. A consumers' purchase decision tends to the equipment with the largest number of features. The use experience, however, can be so complex that it leads to a so-called "Feature Fatigue" effect (Thompson et al., 2005). Feature Fatigue could correspond to $50 \%$ of product returns in the USA (Surowiecki, 2007).

Additionally, the possibility to buy devices with a large number of features at a reduced incremental cost has contributed to an expansion of consumption of products that become rapidly obsolete. These are equipment, therefore, that will be considered outdated in a short timespan because of the new products launched with better or more features, triggering a phenomenon known as "IT Fashion".

On the other hand, a significant trend has been at work in the personal electronics market in the past ten years, affecting organizations in particular: the tendency of technology to spread from the user to commercial and public environments, called the "Consumerization of IT" (Shuster, 2011). The increase in processing power and resources of these devices (Sen, 2012), which enabled the expansion of available service functionalities in a single device, is especially important in this context (Chaka, 2012; Goul et al.,2012).

Apart from the increasing interest they've awakened in academic research, these three research subjects are similar because of their connection to a new social context of technological impact. The consumer's need to frequently exchange his equipment for more modern products, which are launched at increasingly smaller time intervals, seems to be related to the ability of organizations to develop new features for their products, which makes consumers prefer them at the time of purchase. However, according to Thompson et al. (2005), the complexity of use could be so significant that it leads to the Feature Fatigue effect.

For authors such as Cooper and Bess (2012), Ginovski (2012) and Sen (2012), individuals are no longer resigned to fact that they can have the best technology at their disposal in their private lives, but not in their professional life, especially as a function of two arguments: the maximization of productivity (Klinc et al., 2008; Devine, 2012; Gupta, 2012) and the maintenance of a flexible lifestyle to work when and where they want (Bernnat et al., 2010).

It is clear, therefore, that an investigation of the possible relations between these three subjects - IT Fashion and Feature Fatigue, and Consumerization of IT and Feature Fatigue - has become important from a scientific point of view in order to reevaluate the concept of Feature Fatigue from a contemporary perspective: a world where the supply and demand for technology have exploded and its customization keeps increasing. To investigate these relationships, this study will therefore try to answer the following questions: (1) Does the IT Fashion phenomenon have Feature Fatigue as consequence? (2) Does the Feature Fatigue concept still make sense when observed in the organizational context, i.e. from the point of view of the Consumerization of IT in a corporate environment?

In addition, this study seeks to contribute to the research in Business Administration. Because it analyzes the described phenomena from a multidisciplinary perspective, it also contributes to the management practice, specifically to marketing managers who are trying to understand the expectations and experiences of consumers, but also to IT managers who need do define governance policies concerning the use of personal equipment by employees and other collaborators in that context.

1 School of Management Graduate Program, UFRGS (Federal University of Rio Grande do Sul).

2 Industrial Engineering Graduate Program, UFRGS.

3 IFRS (Federal Institute of Rio Grande do Sul)

4 Management Department, UFPel (Federal University of Pelotas)

*Corresponding author: rafael.brinkhues@caxis.ifrs.edu.br

ISSN: 0718-2724. (http://jotmi.org)

Journal of Technology Management \& Innovation (c) Universidad Alberto Hurtado, Facultad de Economía y Negocios. 


\section{Theoretical Framework}

The theoretical framework of the three guiding concepts of this work was investigated in order to characterize the idea of Feature Fatigue based on the proposition of Thompson et al. (2005), and especially, to import and translate the idea of IT Fashion to the individual's universe, given that the concept has its foundations in the field of organizations. We also sought to consolidate one concept of Consumerization of IT, which is a relatively recent phenomenon, although significant in so far that it proposes a new way for individuals and organizations to relate with the technology.

\section{Consumerization of IT}

For the great majority of authors, Consumerization of IT means combining the corporate and personal use of technology devices or applications, causing what it is said to be "the growing influence that our technology experiences as consumers - both hardware and software - have on the technology that we expect to use at work" (Forrester, 2011, p. 2).

For Moschella et al. (2004) the defining aspect of Consumerization of IT is exactly the concept of dual use; Carter et al. (2011) identifies it as a potential change that has been occurring in the use of ICTs. Cazier and Hopkins (2011) associate it with the idea that it's the younger workers who are driving changes based on their own interactions with technology. Other authors summarize it as the tendency of consumer products and technologies to enter the corporate space (Cummings et al., 2009; Prete et al., 2011; Cohen, 2012; Gordon, 2012; Gupta, 2012). More specifically, Grasso and Convertino (2012) claim that it's a diffusion process of Web 2.0 tools from the consumer space to the organizational space. Lamy and McQuire (2010) connect both concepts by stating that Consumerization takes two forms: first there's the pressure exerted by employees to use their personal electronic devices on corporate networks in order to increase productivity, and second there is the increasing prevalence and adoption of social Web 2.0 tools such as LinkedIIn $n^{\mathrm{mw}}$, Facebook ${ }^{\mathrm{mw}}$ and Twitter ${ }^{\mathrm{min}}$ in a corporate context.

Although some see Consumerization of IT as a synonym for "Bring your own device" or "BYOD" (Love, 2012), others prefer to understand it as a more complex process that involves more than the corporate use of personal devices (Burger, 2012), relating directly to increased user control and interaction with IT resources (Sen, 2012). In fact for Chaka (2012) it's as a disruptive force that operates similarly in the IT ecosystem as the proliferation of PCs and the internet did decades ago. The BYOD phenomenon is only one method by which Consumerization can occur. Cooper and Bess (2012), on the other hand, extend the BYOD concept by stating that it's not only about devices, but also about secure, flexible and easy access to corporate information.

Using another nomenclature, Forrester refers to Consumerization as technological populism (Cameron, 2008), giving rise to the idea that it's not only a trend driven by technologically native workers, but also a movement in which the individual, and not organizations, drives technological adoption (Katz et al. , 2008; Klinc et al., 2008; Plummer et al., 2008; Klinc et al., 2009).

For some authors (Cooper and Bess, 2012; Ginovski, 2012; Sen, 2012), individuals are no longer resigned to fact that they can have the best technology at their disposal in their private lives, but not in their professional life, especially as a function of two arguments: the maximization of productivity (Klinc et al., 2008; Devine, 2012; Gupta, 2012) and the maintenance of a flexible lifestyle to work when and where they want (Bernnat et al., 2010). Increasingly, users of all levels wish to have the same access to business, entertainment, government and many other types of personal information as they have through tools like Google (Burton et al., 2006).

Synthesizing this reality, some authors defend that it's the blurring of boundaries between the personal and professional life which, in fact, led to Consumerization (UIowa, 2007; Klinc et al., 2008; Gens et al., 2011; Olden, 2011; Chaka, 2012; Cooper and Bess, 2012; Sen, 2012).

For Cameron et al. (2008) a combination of factors, such as the coming of age a technologically native work force, the ubiquity of broadband (Sen, 2012), and the proliferation of computational collaboration and socialization applications (Yourdon, 2011; Chaka, 2012, Sen, 2012), enhanced by a culture of collaboration (UIowa, 2007), has led to this phenomenon.

Gens et al. (2011) emphasize the aspect of mobility (Yourdon, 2011), in particular, as key-factor, given that the demand for smartphones, tablets and notebooks continues to accelerate to the detriment of traditional devices. The increase in processing power and resources of these devices (Sen, 2012), which enabled the expansion of available service functionalities in a single device, is especially important in this context of Consumerization. Especially when we take into account that many devices are designed exactly for integration (Chaka, 2012; Goul et al.,2012). In addition to these factors, the large-scale adoption of the public cloud is also a facilitating agent of this process (Forrester, 2011; Prete et al., 2011; Yourdon, 2011).

Gordon (2012) is more specific and argues that, similarly to the adoption of Blackberry devices over a decade ago, it was the messaging and calendar features, which today are web based, that led to the largescale adoption of new devices, providing a friendly and fun experience for the consumer.

For Moschella et al. (2004) the consequences for organizations in the long term, include: radically reduced costs (Sen, 2012), improvement of features through a variety of new products, services and innovative applications, in addition to successive generations of users who are increasingly technologically savvy. Others add that competitiveness is increased (Forrester, 2011), business growth and productivity are accelerated through trust (Sen, 2012), the time required for the execution of tasks is reduced (Titus et al., 2012) and that efficiency is increased (Wong, 2012). From a broader perspective, and bypassing the objective questions of productivity and ubiquity, Shehadeh (2008) associates Consumerization to the improvement of quality of life. 
Carter et al. (2011) address the psychological aspect of Consumerization by stating that young people develop emotional bonds with the ICTs with which they interact daily; Gupta (2012) refers to this as an alternative way to conceptualize user needs, which he classifies in three dimensions that work interactively: (1) Nice to have; (2) Good to have; (3) Must have. These elements could suggest that there may be additional components aside from performance that determine the technological choice by the user, possibly guided by a collective belief that associates Consumerization to novelty, efficiency and vanguard, all elements that are present in the concept of IT Fashion.

\section{IT Fashion}

Why do organizations adopt innovations? Most attempts to answer this question can be divided into two main schools of thought. On the one hand, the economic-rationalist perspective focuses on organizational performance and deals with the degree to which an organization achieves its goals, often measured in financial or economic terms (Wang, 2010). On the other hand, the institutional perspective emphasizes organizational legitimacy, which refers to a general perception or assumption that the actions of an organization are desirable or appropriate within the organization's environment of socially constructed norms, values and beliefs (Suchman, 1995).

The concept of Fashion fits into this innovation path. Just as with innovation, fashion is becoming a common phenomenon in information and communication technologies. Just like research and management, IT is in fact characterized by fashion trends. These waves of "IT Fashion" are relatively transient and represent an explosion of interest in specific topics by both researchers and professionals (Baskerville and Myers, 2009).

The concept of IT Fashion emerged based on the concept of "Management Fashion", which is a relatively transitory collective belief that an administrative technique is new, efficient, and at the forefront of management practice (Abrahamson, 1996). IT Fashion is a transitory collective belief that an information technology is new, efficient, and at the forefront of IT practice (Wang, 2010). Similarly, Benders et al. (2001) state that IT Fashion indicates the intense, but temporary production and consumption of an IT discourse.

New information technologies are emerging constantly and, as Wang (2010) found in his study, those organizations that follow IT Fashion are more admired, and although they do not always overcome their competitors, they do often have a better performance.

Fashion and fashion adoption build on each other, each supporting the other in a self-reinforcing cycle. When organizations start adopting a technology in an ongoing basis, a fashion trend starts to develop. However, it should be noted that when compared to Management Fashion, the high costs of transfer could make the practice of IT less prone to the inconstancies of fashion (Wang, 2010).

Taking the concept of IT Fashion from the domain of organizations and applying it to the scope of the individual, particularly in the context of the Consumerization of IT, we can observe that having a technologically advanced device represents not only a search for per- formance, but also for legitimacy. Because they expect to increase their productivity at a bearable cost, people may therefore choose to purchase or use the most recent developments in IT as a way of creating value for themselves.

\section{Feature Fatigue}

Feature Fatigue is reflected in the difficulty of the user to operate products with a large number of features (Thompson et al., 2005). The increase in functions of devices in relatively cheap for factories, which can offer them for a small incremental price. At the time of purchase, the consumer considers such an offer more attractive and tends to prefer the products with the greatest number of features. Later, the challenges with which the consumer is faced to use the product make him stop using it, or even return it.

Based on this idea, two elements can be highlighted: capability and usability (Rust et al., 2006). In the purchase decision, more weight is given to a product's capability. A negative user experience, however, may harm consumer satisfaction and his overall evaluation of the product.

In three studies the authors confirmed that an increase in the number of features has a positive effect on the perceived capability by consumers, but a negative effect on usability. Increased usefulness is therefore related to the balance in the amount of important features for each product (Thompson et al., 2005). These results indicate that even market research may not eliminate the problem of Feature Fatigue. It is therefore important that consumer consultations take the dimension of usability into account to measure satisfaction in the long term (Thompson et al., 2005).

Given that the majority of purchasers doesn't use all the features of their highly complex devices, companies should focus on producing simpler products. A good performance of the main features increases the usability at the expense of a large number of features (Thompson et al., 2005).

Balancing the attractiveness at the time of sale because of the high number of features, with the usability and satisfaction in the long term can avoid the bigger problems associated with Feature Fatigue - product returns and a possible negative impact on the product's brand.

Effort has therefore been put into research to search for ways to mitigate this phenomenon, and a series of models for the assessment of Feature Fatigue have been developed to help manufacturers at the design stage of their projects (Li and McQuire, 2011; Li et al. 2012).

The solution to this problem can therefore not be reduced to the exclusion of features in technological devices, but lies instead in a better product design to reduce the effect of Feature Fatigue (Rahman and Rahman, 2009).

\section{Method}

Two techniques were employed in order to meet the objectives of the study: the laddering methodology, which is a very useful tool to identify the benefits and personal values that are important to the 
consumer (Saaka et al., 2004) and a quantitative survey, which, according to Pinsonneault and Kraemer (1993), is a way to collect data and information about actions, opinions or peculiarities of a certain group of people who represent a target population through the use of a questionnaire.

The laddering method is a tool to study personal values as applied to marketing, reflecting a more profound relationship between the consumer and the products. It establishes the cognitive positions that consumers have in relation to products, enabling the marketer to develop strategies for the positioning of new products (Reynolds and Gutman, 1988). According to the instructions of Reynolds and Gutman the laddering method should be divided into two main stages: first, the collection of data, and second, the interpretation of data.

With regard to data collection, the laddering method starts with the completion of an in-depth personal interview based on a semi structured script. The interviews play an important role in the qualitative research because they give you access to the representations and descriptions of routines present in the lives of individuals, representing important sources of information. It is assumed that these interviews are an accurate portrayal of reality (Oliveira et al., 2009). The advantage of in-depth interviews face to face is that there is no significant time delay between question and answer and, as such, the answer of the interviewee is more spontaneous, without an extended reflection (Opdenakker, 2006).

Twelve interviews were carried out following the guidelines for the laddering technique in order to meet the research objectives of investigating whether IT Fashion can lead to Feature Fatigue in the context of an individual. Since this was an exploratory study that used a quantitative approach, it presented a hierarchy of values that connect the atributes of the product sequentially with (A) the consequences of the use of the product, (C) personal values $(\mathrm{V})$ of each consumer, forming an $\mathrm{A}-\mathrm{C}-\mathrm{V}$ chain. This is also known as a means-end chain, where the means are the products and the ends are the personal values (Saaka et al., 2004).

After the data collection for this step of the method, the date was analyzed and interpreted to identify if there was any dynamic present between IT Fashion and Feature Fatigue from an individual perspective. The second stage of the research consisted of a survey that sought to compare the Feature Fatigue among consumers that used the equipment inside and outside the organizational environment. Before applying this technique, a pre-test was realized in order to refine the instrument. The survey was then applied to the students of three universities. The applied questionnaire was adapted from the study by Thompson et al. (2005), and divided into seven blocks, as follows:

- $\quad$ Block 1 - Features (three items)

- $\quad$ Block 2 - Usability (eight items)

- Block 3 - Expected utility of the product (six items)

- $\quad$ Block 4 - Skills (five items)

- $\quad$ Block 5 - Satisfaction (four items)

- Block 6 - Use of the phone (ten items)

- Block 7 - Qualifying variables (eight items)
The introduction of the questionnaire presents an image of six smartphones with a wide range of features. The respondent was invited to answer the questions considering one of these devices or their equivalent. In block 6 a question was included to divide the sample into respondents with and without experience in the use of these devices. This sample division enabled us to evaluate the expectation of use and satisfaction based on the premise of the study by Thompson et al. (2005) that expectations are greater than the satisfaction.

Finally, three questions were also included in block 6 to assess the incidence of the Consumerization of IT in the daily lives of respondents. Based on these questions it was possible to separate the sample and compare if Feature Fatigue also occurs in the organizational environment.

\section{Methodological Procedures of the Laddering:}

The semi structured script of the laddering was composed of seventeen guiding questions. These were used to leverage answers that linked the attributes to the consequences and values. In some cases, the depth of the answer to any of the questions eliminated the need to ask other questions. Additional questions were included when necessary, on the other hand, according to the development of the interview.

To check the relationships between IT Fashion and Feature Fatigue, we explored the respondent's experience with his current smartphone and its features. During the interview the respondent was invited to reflect and compare the features of his current device, including their use, with his previous device. At the end of the interviews, four questions were asked to classify the respondents. Particular details of this procedure are as follows:

- twelve interviews were conducted (one was discarded because it didn't fit the target sample, leaving six men and five women).

- The interviews were held on November 27 and 28, 2012, in a study room of the library of the School of Administration of UFRGS.

- The respondents were all undergraduate students of the Business Administration course, with active registration, between twenty one and thirty four years old.

- The interviews were held in the morning and evening shifts and lasted between ten to fifteen minutes, each.

- The interviews were recorded on audio and video.

\section{Methodological Procedures of the Survey:}

The following statistical procedures were applied to analyze the data generated by the survey:

The pre-test consisted in applying the draft questionnaire to thirty university students. It was conducted on November 30, 2012. The results of the pre-test were analyzed item by item according to frequency distribution and univariate statistics (mean, median and standard deviation), in addition to calculating the index of reliability shown below. 
Adjustments were made in the questionnaire related to the question order and with respect to the clarity of the writing in order to improve the reliability of responses. We also included additional variables related to smartphone use, which arose from the analysis of the responses obtained in this step (in particular in relation to the assessment of Consumerization). Based on the responses in this phase, the wording and order of questions was also adjusted in order to improve the segmentation of the sample to evaluate expectation and usability. The population, of an undefined nature, followed the references for respondent profiles of the seminal article on Feature Fatigue (Thompson et al., 2005) in order to collect responses from university students. Out of convenience, the sample was taken from seven courses from three universities in the cities of Porto Alegre, Pelotas, Caxias do Sul, Cachoeirinha, Guaiba and Passo Fundo, all in the state of Rio Grande do Sul. The questionnaires were administered in the classroom, faceto-face, through a physical instrument, to one hundred fifty-three respondents. Data was gathered between December 05, 2012, and January 04, 2013.

According to Hair et al. (2009), variables or cases with more than 50\% of lost data should be eliminated, but, to the extent that the level of lost data decreases, the researcher should increase this cut-off criterion. For Kline (1988), on the other hand, the data omitted must not exceed $10 \%$ of the responses for a variable. Based on these guidelines, a case was excluded if $55 \%$ of the data was lost, thus exceeding the limits proposed by both Kline (1998) and Hair et al. (2009). After this procedure, the sample consisted of one hundred fifty-two respondents.

Following the guideline proposed by Roth (1994), who suggests the elimination of cases in which an entire block is left unanswered, two more respondents were excluded who did not provide data for block 3 of the instrument, leaving a sample with one hundred and fifty valid cases.

The presence of randomness of omission (MAR - Missing at Random) was also verified, given that the lost data did not reveal a systematic pattern (Hair et al., 2009). To establish this the MARC test was used, which indicated randomness in the omitted data with a significance level of 0.75 .

The Kolmorogov-Smirnov test indicated the normality of the sample data for the first twenty six variables. The Crombach Alpha was calculated for the instrument (first twenty six and interval variables), obtaining an Alpha of 0.913, and a Crombach Alpha, based on the standardized items, of 0.919. The Crombach Alpha of the pre-test, after the exclusion of two respondents (excessive data loss - above $50 \%$ ), was 0.920 .

The sample was composed of sixty six male and eighty three female subjects, representing $44 \%$ and $55.3 \%$, respectively. The mean age of respondents was twenty five years old, with a minimum value of seventeen and a maximum of fifty two years old.

With respect to income, $46.7 \%$ of respondents had incomes of up to U\$ 475.00, while $18 \%$ earned more than U\$ $1,400.00$. It is important to stress that $6 \%$ chose not to answer this question.

Regarding occupation, 30\% were interns, $36 \%$ were officially employed (CLT), $11 \%$ were public officials and $20 \%$ were only students.
Regarding the course, $54.7 \%$ of respondents attended the Business Administration course, while the rest could be divided between Mathematics, Technical Professional courses, Law, Public Administration, International Relations, Metallurgical Processes, Public Relations, Advertising and Publicity, Archival science and Librarianship. As to the origin, 54\% were students of UFPEL university (city of Pelotas), $22 \%$ of IFRS university (city of Caxias), 20\% of UFRGS university (city of Porto Alegre) and 4\% of the universities: FARGS (city of Porto Alegre), PUCRS (city of Porto Alegre), ULBRA (city of Canoas), CESUCA (city of Cachoeirinha) and UPF (city of Passo Fundo).

With respect to the electronic device, $68 \%$ of the sample had some type of smartphone, and regarding its use, $54 \%$ of respondents used it only for personal purposes, while $43.3 \%$ used it for personal and professional purposes. In most cases, the phone was property of the respondent. Only $5 \%$ of devices were made available by the company where the respondents worked.

After considering the use, or not, by valid respondents of the device within the company, it was possible to divide the sample into two equal groups, with $49.7 \%$ of respondents saying they use the phone inside the company, and an equal percentage saying they don't do this, mostly because of restrictions of the company. When network access was considered, $40.9 \%$ of respondents said that the company in which they work does not allow Internet access through the corporate wireless network, and $61.2 \%$ stated that the company allows the use of the device for access via the $3 \mathrm{G}$ network. The most popular carrier among respondents was $\mathrm{Claro}^{\oplus}(25 \%)$, followed by $\mathrm{Oi}^{\oplus}$, $\mathrm{Tim}^{\star}$ and $\mathrm{Vivo}^{\oplus}$ with approximately $20 \%$ each. Four respondents reported using another carrier and twenty one did not respond.

\section{Results}

In this section the results are presented and analyzed in two steps: first, the implications of the laddering study are presented and then the results of the statistical analysis of the data obtained through the survey.

\section{Laddering}

The goal of this first stage of the study was to observe the relations between the two investigated subjects through laddering interviews. Based on an analysis of the interviews we tried to verify whether the IT Fashion phenomenon had Feature Fatigue as consequence. The results provide tenuous support that IT Fashion can contribute to Feature Fatigue. As can be seen in Figure 1, there were only two occurrences where the respondent indicated that the attributes (excess of features) led to the disuse of the device.

However, other attributes had a greater frequency of responses, which enabled us to identify relevant relationships for the explanation of the behavior of individuals regarding equipment that was acquired within the criteria for IT Fashion. Even though this was expected given the characteristics of the product used as a reference, the attribute that returned the largest frequency was internet access (with forty one occurrences), leaving behind other traditional functions of mobile phones, such as voice calls (1) and SMS Messages (3). This attribute, 
however, produced four other sub-attributes: electronic mail (7); access to information (2); access to social networks (7) and instant messaging (5). The remaining attributes with more than two occur- rences did not present sub-attributes. Only one Means-End chain was complete with at least two attribute-consequence-value occurrences: brand (7) è legitimation è social acknowledgment (2).

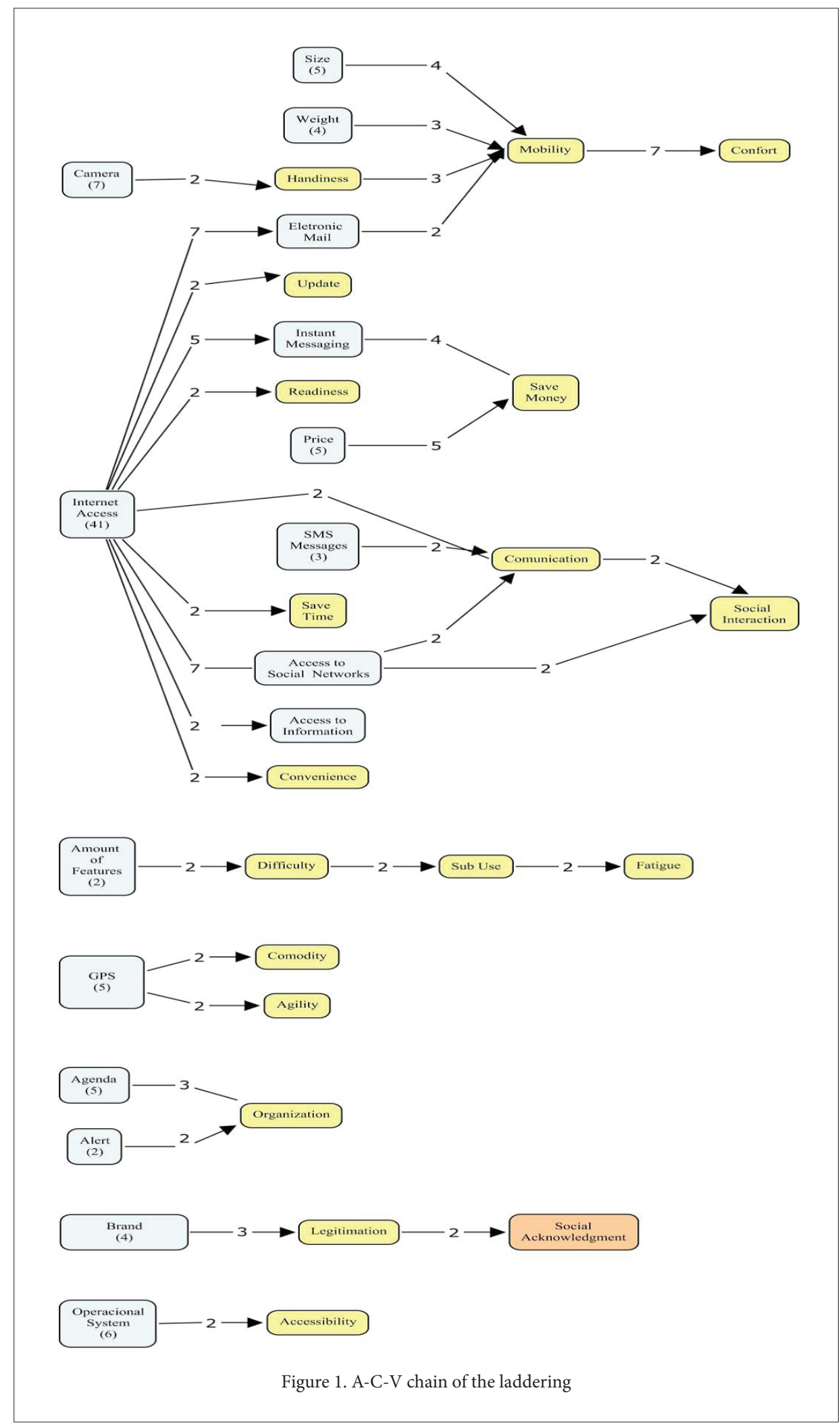


Most identified chains reached the level attribute-consequence. This did not harm the study, since the objective of employing this technique was not to search for values, but rather to establish relationships between the attributes and their consequent. Just as was the case with the Internet access attribute, which generated other attributes, there was also the occurrence of more than one level of consequences. The physi$\mathrm{cal}$ attributes weight and size, in particular, converged to more than one consequence, until the last level, comfort. The consequent comfort was also related to other attributes, such as e-mail and camera.

In addition to these chains that shared consequents, they also shared consequences, such as SMS and price. Other chains, however, were isolated, with an attribute related only to one consequent (and its subsequent levels), or, at most, to similar attributes. Agenda (5) and alert (2), for example, shared a single consequent, organization (5). These attributes of an established intensive use in cell phones (which had low frequency), such as voice call and SMS, had a high occurrence. This considering thef fact that the studied equipment were smartphones with a wide range of features. Regarding the association between IT Fashion and Feature Fatigue, two occurrences suggested that the second phenomenon is strengthened by the first. A chain formed from the high amount of features (2) that the current smartphones have, leading to a greater difficulty (2) to use of equipment, generating its sub-use (2). These consequents coincide with the findings of Thompson et al. (2005) on Feature Fatigue (2). One of the respondents even stated that because of this difficulty he downgraded his phone, exchanging his device for one with a smaller number of features.

\section{Survey}

To check for differences between the behavior of two groups: those who practice Consumerization and those who don't (non-Consumerization), a prior division of the sample was made. To analyze if Feature Fatigue would have the same effect in the Consumerization group, we first had to check if the Feature Fatigue phenomenon was present. To achieve this, we looked for differences between the expectation of use and experience of use groups. The sample was divided according to question 6.1 (which made a distinction between experience and expectation of use), classifying the respondents with experience of use as 1, and those with expectation of use as 2, creating the relabeled variable T6.1.

The first difference tests were performed with the above presented division. The remaining tests were carried out by adding a second division: Consumerization and non-Consumerization. The Consumerization group was identified as 2, and the non-Consumerization group as 1, based on the answers to questions 6.6 and 6.8. The variable resulting from the intersection of these two variables was called T6.6.8.

With respect to Block 1, the Levene test revealed that the sample of the two groups were homogeneous for V1.1 and V1.3, because the pvalue exceeded 0.05 (0.502 and 0.118$)$. In the same way, the T-test indicated that the groups did not show differences between the averages in V1.1 and V1.3 (see the first line, equal variances assumed: 0,496 and 0,161 ). In the variables V1.1 and V1.3 the confidence interval can be considered null, since it contains the zero.

However, for V1.2, the Levene test pointed to the homogeneity of the samples, with a significance level below 0.05 (0.028). In this case, the second line of the T-test was observed, equal variances not assumed, where the significance was of 0.009 with an interval of 0.13213 to 0.90619 . This shows that for this item (V 1.2) there are significant differences between the experience of use and expectation of use samples.

As for Block 2, of the eight items only the first, V 2.1, was not significant $(0.12)$. For the others the T-test indicated that there are significant differences between the two samples (use and expectation), taking into account homogeneity or non-homogeneity through the Levene test.

For Block 3, only V 6.3 showed significance for the question whether there is difference between the samples (0.38).

Block 4 had a similar result as block 2. It indicated significance of variance between the samples for all items, except for item 4.2. Similarly, in the last block only item 5.4 showed no significant difference between the variance of the samples.

The T-tests per variable, therefore, indicated few items with a significant differences between the expectation and experience of use groups. In block 1, this was only the case for V1.2, indicating that there is a difference in the perception of the advantages resulting from the features of the tool between the two groups. In block 2, on the other hand, the results revealed significant differences for all usability items, except for the capacity to understand and use the device by trial and error.

Block 3 also indicated a greater homogeneity than significant differences in the results. Only V6.3 presented different results between the two groups, indicating that the expected usefulness of the device is different than the perception of usefulness of those using the device.

Block 4, which posed questions about skills, also revealed differences between both groups, except with regard to the need of knowing the characteristics of the product beforehand. Finally, block 5 also revealed differences for all items, except for the one referring to the difficulty of the purchase decision.

Subsequently, we performed a MANOVA to check for differences in use experience and use expectation in the Consumerization and nonConsumerization groups, considering both independent variables tested by the block variables as dependent variables.

The first test was carried out by testing all the twenty six questions. There were significant differences between the groups T6.1 (expectation and use) and T6.6.8 (Consumerization), but when crossed no differences were found. That is, the experience group did not reveal any difference between Consumerization and non-Consumerization. The same occurred with the expectation group. 
In the following tests, we analyzed differences by blocks (as dependent variables) and the same differences between groups as independent variables.

Block 1, which deals with the perception of features, only revealed differences between the experience and expectation of use groups. The difference between the Consumerization and non-Consumerization group did not prove to be significant.

On the issue of usability studied in block 2 , the results indicated that there are differences between the groups, both for the experience and expectation of use and the Consumerization and non-Consumerization groups. However, the crossing of both groups did not reveal any significant variation.

The block of items that aimed to evaluate the perception of product usefulness did not behave like block 1, revealing differences only between the Consumerization and non-Consumerization groups. The expectation and use samples did not show any significant differences in their means.

Finally, blocks 4 and 5, which measured skills and satisfaction, behaved the same way, with differences only showing up in relation to the expectation and experience of use groups.

Both generally and by blocks no significance was therefore observed when crossing the T6.1 and T6.6.8 variables, indicating that there is no difference between the use and expectation effects and the Consumerization and non-Consumerization effects. Not one case revealed a significant difference in the crossing of the four groups: experience of use, expectation of use, Consumerization and non-Consumerization.

\section{Concluding Remarks}

The present work investigated the existing relations between three concepts that, although distinct, are all related to the same context of technological transformation: Consumerization of IT, IT Fashion and Feature Fatigue. The methodology employed two research steps: a laddering study followed by a survey in order to identify whether Feature Fatigue could be observed in the context of IT Fashion or Consumerization of IT.

In his seminal article, Thompson et al. (2005) investigated the presence of Feature Fatigue in users of music players almost a decade ago. Similarly, this study focused its research on the smartphone to study the phenomena mainly because it is a contemporary technology of large and growing social penetration, which is used especially by young people. These electronic devices are characterized by the fact that they are not merely individual devices, but an interconnected technological platform with multiple features that enable the use of social networks, which have been attracting the interest of all social segments, especially young people.

Albeit tenuously, the results of the laddering provide some evidence that consumption motivated by IT Fashion leads to the so-called Feature Fatigue effect. The in-depth analysis of the laddering interviews reinforces this assessment, since the statements of users obtained after detailed observation do not demonstrate, in most cases, the occurrence of disuse of features. Results that were reported by Thompson et al. (2005).

Analyzing the use of smartphones by university students, we observed the occurrence of Feature Fatigue at relatively low levels, as evidenced by the only slightly significant difference found between the expectation (those without experience in the use of their smartphone features) and the experience (who declared themselves as users) groups.

A possible explanation for the differences between the results of this study and Thompson et al. (2005), that is, for the lower occurrence of Feature Fatigue in the researched products, could perhaps be credited to the level of customization and adjustment that can be observed in the latest smartphones, which have adopted apps that can be added, modified and replaced as the standard tools to develop and upgrade their products. This becomes significant in so far that it lets users determine which features they want to install or maintain, ensuring independence and the satisfaction of their real needs, instead of the user being forced to learn to use those features determined by the manufacturer of the product.

With respect to the Consumerization of IT, our study did not reveal significant differences between the users of the defined samples with the separation of the groups into those who make only personal use of the equipment and those that also use it professionally, both inside and outside the company. The patterns observed through the survey suggest that the behavior for using technology is quite similar for the cases where Consumerization of IT is observed and those where it isn't. In line with the literature, which characterizes Consumerization of IT as the trend towards dual use (personal and professional) of electronic devices, the analyzed sample reveals a significant number of cases that fall in this category.

The customization of products, such as smartphones, also strengthens the Consumerization of IT trend, in addition to the analogous behavior in those cases where it is not observed, given that specific applications can be suited for either professional or personal use in different locations, interchangeably. The study suggest, therefore, that the influence of IT Fashion is significant in relation to Feature Fatigue, although this effect proves to be less pronounced than would be expected based on the literature. The context of Consumerization of IT, on the other hand, could be observed, but it didn't reveal significant differences regarding the impact on Feature Fatigue, revealing the same behavior between both groups.

\section{Study Limitations and Suggestions}

The present study was applied to a specific product, within the context of analysis and with limited reach, which means the results cannot be generalized. New studies with a greater geographic reach and that consider technologies that have a different application or scope, may be interesting to confirm or reject the results found in this study.

Additionally, the laddering results suggest future lines of research. 
From changes in consumer behavior to the development of new features, the configuration of the generated map reveals various chains that could be explored not only by academic research, but also by those organizations involved in the production of equipment, systems and content for mobile devices.

\section{References}

Abrahamson, E. (1991). Management fashion. Academy of Management Review, 21(1), pp. 254-285.

Baskerville, R. L., \& Myers, M. D. (2009). Fashion waves in information systems research and practice. MIS Quarterly, 33(4), pp. 647-662.

Benders, J., \& Van Veen, K. (2001). What¥s in a fashion? Interpretative viability and management fashions. Organization, 8(1), pp. 289-309.

Bernnat, R., Acker, O., Bieber, N., \& Johnson, M. (2010). Friendly Takeover The Consumerization of Corporate IT. Booz \& Company, Frankfurt.

Burger, K. (2012). Resistance Is Futile. Bank Systems + Technology, p. 6.

Burton, B., Geishecker, L. S., Hostmann, B., Austin, T., Herschel, G., Soejarto, A., \& Rayner, N. (2006). Business Intelligence focus shifts from tactical to strategic. Gartner Research, Stamford. Acesso em 13 de 06 de 2012, disponIvel em Gartner: http://www.gartner.com/id=492462

Cameron, B., Cullen, A., \& Worthington, B. (2008). The emerging technology trends that CIOs should care about. Forrester Research Inc., Cambridge. Acesso em 10 de 04 de 2012, disponİvel em Forrester For CIOs Professionals: http://www.forrester.com/The+Emerging+Technology+Trends+That+CIOs+Should+Care+About/fulltext/-/E-RES46357? docid $=46357$

Carter, M., Thatcher, J. B., Applefield, C., \& Mcalpine, J. (2011). What cell phones mean in young people¥s daily lives and social interactions. Southern Association for Information Systems Conference. Atlanta.

Cazier, J. A., \& Hopkins, B. E. (2011). Doing The Right Thing for the Environment Just Got EasierWith a Little Help from Information Systems. Sprouts - Working Papers on Information Systems, pp. 1-7.

Chaka, C. (maio de 2012). Consumerization of IT, Social Computing, and Mobility as the New Desktop. Cutter IT Journal, pp. 28-33.

Cohen, B. (maio de 2012). The Effects of Consumer-Driven Innovation. Cutter IT Journal - Journal of Informatio Technology Management, 25, pp. 6-10.

Cooper, J. C., \& Bess, C. E. (maio de 2012). BYOD Is Not Really About Devices. Cutter IT Journal, pp. 20-27.

Cummings, J., Massey, A. P., \& Ramesh, V. (2009). Web 2.0 Proclivity: Understanding How Personal Use Influences Organizational Adop- tion. 27th ACM international conference on Design of communication (pp. 257-264). New York: ACM.

Devine, S. M. (abril de 2012). Interview: BYOD and the enterprise network. Computer Fraud \& Security, pp. 14-17.

Forrester. (2011). IT managers selectively embrace Consumerization. Forrester Research Inc., Cambridge. Acesso em 15 de 05 de 2012, disponIvel em Microsoft: http://download.microsoft.com/ download/B/3/A/B3ABAFBF-B96E-496A-8A96-51EAE5091C07/ IT\%20Managers\%20Selectively\%20Embrace\%20Consumerization_FINAL\%20 02172011.pdf

Gens, F., Levitas, D., \& Segal, R. (2011). Consumerization of IT Study : Closing the "Consumerization Gap". IDC. Framingham: IDC Goto-Market Services.

Ginovsky, J. (abril de 2012). "BYOD” quandary: when the "bring your own device" trend comes to the bank,"BYOD" quandary: when the "bring your own device" trend comes to the bank, measure the risks carefully. ABA Banking Journal, p. 24.

Gordon, D. (maio de 2012). What the PC Revolution Can Teach Us About the iConsumerization of ITî. Cutter IT Journal, pp. 11-15.

Goul, M., Marjanovic, O., Baxley, S., \& Vizecky, K. (2012). Managing the Enterprise Business Intelligence App Store: Sentiment Analysis Supported Requirements Engineering. 45th Hawaii International Conference on System Sciences (pp. 4168-4177). Maui: IEEE Computer Society.

Grasso, A., \& Convertino, G. (2012). Collective Intelligence in Organizations: Tools and Studies. Computer Supported Cooperative Work, 21(4-5), pp. 357-369.

Gupta, M. K. (maio de 2012). The Consumerization of IT and Its Impact on Enterprise Business Applications. Cutter IT Journal, pp. 16-19.

Hair Jr, J. F., Anderson, R. E., Tatham, R. L., \& Black, W. C. (2009). An-lise multivariada de dados (6 ed.). PORTO ALEGRE: BOOKMAN.

Katz, R., Goldstein, P., \& Yanosky, R. (2008). Cloud Computing in Higher Education. Acesso em 15 de junho de 2012, disponİvel em Educause: http://net.educause.edu/section_params/conf/CCW10/ highered.pdf

Klinc, R., Dolenc, M., \& Turk, Z. (2008). Possible benefits of Web 2.0 to construction industry. CIB W78 25th International Conference on Information Technology in Construction. Santiago: International Council for Research and Innovation in Building and Construction .

Klinc, R., Dolenc, M., \& Turk, Z. (2009). Engoineering collaboration 2.0: requirements and expectations. (A. S. Kazi, G. Aouad, \& A. Baldwin, Eds.) Journal of Information Technology in Construction, pp. 473-488. 
Kline, R. B. (1998). Principles and practices of structural equation modeling. New York, NY: Guilford.

K^ffer, S., Fielt, E., \& Niehaves, B. (2015). IT consumerization and its effects on IT business value, IT capabilities, and the IT function. PACIS 2015 Proceedings: Pacific Asia Conference on Information Systems. The Association for Information Systems (AIS).

Lamy, L., \& McQuire, N. (2010). The consumerization of IT: how are CIOs managing the complexity. Unisys. Fonte: Unisys.

Li, M., \& McQuire, N. (2011). Feature fatigue analysis in product development using Bayesian networks. Expert Systems with Applications, 38(8), pp. 10631-10637.

Li, M., Wang, L., \& Wu, M. (2012). A multi-objective genetic algorithm approach for solving feature addition problem in feature fatigue analysis. Journal of Intelligent Manufacturing, 23, pp. 1-15.

Li, M., Wang, L., \& Wu, M. (2014). An integrated methodology for robustness analysis in feature fatigue problem. International Journal of Production Research, 52(20), pp. 5985-5996.

Love, J. (janeiro de 2012b). The Consumerization of IT: Predictions, Wishes, and Dart-Throwing Monkeys. Cutter IT Journal, pp. 18-23.

Melin, U., Sarkar, P. K., \& Young, L. W. (2014). Fashions in the Cloud: A case of Institutional Legitimacy. Twentieth Americas Conference on Information Systems, (pp. 1-12). Savannah.

Monteiro, D. P. (2010). O conceito de valor para o consumidor uma an.lise sob a Ûptica da metodologia Laddering. DissertaÁ,o de Mestrado em CiÎ́ncias da ComunicaÁ,o, Marketing e Publicidade, Universidade LusÛfona de Humanidades e Tecnologias, Lisboa.

Moschella, D., Neal, D., Opperman, P., \& Taylor, J. (junho de 2004). The ëConsumerizationí of Information Technology. CSC. London: Computer Sciences Corporation.

Oliveira, M., Rego, B., Alves, D., Machado, F., \& Slongo, L. (2009). Uma comparaÁ,o entre entrevista face-to-face e entrevista on-line via chat, aplicando-se a tĖcnica laddering. Gest,o e Regionalidade, 25(75), pp. 57-72.

Opdenakker, R. (2006). Adantages and disadvantages of four interviews techniques in qualitative research. Forum Qualitative Sozialforschung, 7(4).

Pinsonneault, A., \& Kraemer, K. L. (1993). Surveyresearch methodology in management information systems: An assessment. Journal of Management Information Systems, 10(2), pp. 75-105.

Plummer, D. C., Smulders, C., Fiering, L., Natis, Y. V., Mingay, S., Driver, M., . . . Wilson, D. (8 de janeiro de 2008). Gartner's Top Predictions for IT Organizations and Users, 2008 and Beyond: Going Green and Self-Healing. Research, Gartner, Stamford.
Prete, C. D., Levitas, D., Grieser, T., Turner, M. J., Pucciarelli, J., \& Hudson, S. (maio de 2011). IT Consumers Transform the Enterprise: Are You Ready? White Paper, IDC, Framimgham.

Rahman, M., \& Rahman, M. M. (2009). To defeat feature fatigue the right way, understand it first. Strategic Direction, 25(6), pp. 26-28.

Reynolds, T., \& Gutman, J. (1988). Laddering Theory, method, analysis and interpretation. Journal of Advertising Research, 28, pp. 11-31.

Roth, P. L. (1994). Missing data: A conceptual review for applied psychologists. Personnel Psychology, 47, pp. 537-560.

Rust, R. T., Thompson, D. V., \& Hamilton, R. W. (2006). Defeating Feature Fatigue. Harvard Business Review, 84(2), pp. 98-107.

Saaka, A., Sidon, C., \& Blake, B. F. (2004). Laddering: A "How to do it" Manual - with a note of caution. Research Reports in Consumer Behavior, pp. 1-34.

Sen, P. K. (24 de fevereiro de 2012). Consumerization of IT - Drivers, benefits and challenges for NZ corporates. School of Information Management, Victoria University of Wellington, Wellington.

Shuster, E., \& Kalamarides, A. (2012). Thriving in a BYOD world. IntelliClear. Colorado Springs: IntelliClear.

Suchman, M. (1995). Managing legitimacy: Strategic and institutional approaches. Academy of Management Review, 20(3), pp. 571-610.

Surowiecki, J. (2007). Feature Presentation. Acesso em 18 de 05 de 2012, disponİvel em The New Yorker: http://www.newyorker.com/ talk/financial/2007/05/28/070528ta_talk_surowiecki

Thompson, D. V., Hamilton, R. W., \& Rust, R. T. (2005). Feature Fatigue: When Product Capabilities Become Too Much of a Good Thing. Journal of Marketing Research, 42, pp. 431-442.

Titus, P., Desai, C. C., Greer, R., Kuhn, J., \& Duckering, B. (2012). State of mobility survey. Survey, Symantec, Mountain View.

UIowa. (2007). The impact of consumer technology. University of Iowa - Tech Forum, Iowa.

Wang, P. (2010). Chasing the Hottest IT: Effects of Information Technology Fashion on Organizations. MIS Quarterly, 34(1), pp. 63-85.

Wong, W. (junho de 2012). BYOD: the risks of bring your own device. Risk Management, p. 9.

Yourdon, E. (2011). Vivek Kundra - First CIO of the USA. In: P. Manning (Ed.), CIOs at work (pp. 299-308). New York, NY: Springer Science. 